\title{
Correction to: Optimization of energy-constrained wireless powered communication networks with heterogeneous nodes
}

\author{
Mohamed A. Abd-Elmagid' (D) Tamer ElBatt ${ }^{2,3} \cdot$ Karim G. Seddik ${ }^{4}$
}

Published online: 23 March 2018

(C) Springer Science+Business Media, LLC, part of Springer Nature 2018

\section{Correction to:}

\section{Wireless Networks}

https://doi.org/10.1007/s11276-017-1587-x

The original version of this article contained error in author affiliation. Also, the article note and acknowledgement sections are missing.

The affiliations of first and second authors were published incorrectly. The correct affiliations are published with this erratum.

\section{Article Note:}

This work was done when Tamer ElBatt was with WINC, Nile University, Egypt.

\section{Acknowledgement:}

This work was supported by a grant from the Egyptian National Telecommunications Regulatory Authority (NTRA).
The original article can be found online at https:// doi.org/10.1007/s11276-017-1587-x.

Mohamed A. Abd-Elmagid

m.abdelaziz@nu.edu.eg

Tamer ElBatt

telbatt@ieee.org

Karim G. Seddik

kseddik@aucegypt.edu

1 Wireless Intelligent Networks Center (WINC), Nile University, Giza, Egypt

2 Electronics and Communications Engineering Department, Faculty of Engineering, Cairo University, Giza 12613, Egypt

3 Computer Science and Engineering Department, The American University in Cairo, AUC Avenue, New Cairo 11835, Egypt

4 Electronics and Communications Engineering Department, American University, AUC Avenue, New Cairo 11835, Egypt 